\title{
O QUE PODEM AS CRIANÇAS?
}

\section{Rosana Aparecida Fernandes* Fabrícia Teixeira Borges}

RESUMO: O que podem as crianças? De que afectos são capazes? O que se passa em uma Comunidade de Investigação Filosófica de forma a alterar os modos como as crianças se inserem nas cenas cotidianas? Quais afecções fizeram determinada $2^{a}$ série do Ensino Fundamental se apropriar de Pimpa e experimentar na fala e no pensamento os conceitos estudados, articulando-os com um acontecimento político que percutiu em Brasilia em 1998?

Palavras-chave: Pimpa; Afectos; Pensar; Intervir; Problematizar.

RESUMEN: ¿Qué pueden hacer los niños? ¿Qué afectos son capaces? ¿Qué se pasa en una Comunidad de Investigación Filosófica para alterar las formas en que los niños se incluyen en las escenas cotidianas? ¿Lo que está ocurriendo en una determinada clase de la escuela primaria de modo a llevar a los niños a vincular Pimpa con un acto político que tocó Brasilia en 1998, ensayando en la habla e no pensamiento los conceptos estudiados?

Palabras Claves: Pimpa. Afectos. Pensar. Intervenir. Problematizar.

Era outubro de 1998 e a paisagem de Brasília, a capital do Brasil, estava tomada pelo processo de eleição para a escolha do próximo governador do Distrito Federal. As crianças da $2^{\mathrm{a}}$ série do Ensino Fundamental de uma escola privada acompanhavam com atenção todos os movimentos referentes à eleição. Havia uma grande torcida daquelas crianças para que o governador Cristovam Buarque fosse reeleito, as mochilas portavam botons, broches, as meninas usavam brincos, abanavam bandeiras, assistiam aos debates, argumentavam, e participavam da eleição como se fossem eleitores. Na primeira aula, seguinte ao dia da eleição, a professora chegou à sala e encontrou a maioria da turma chateada, triste, decepcionada. O candidato favorito das crianças tinha perdido a eleição. Mas a professora precisava começar a aula, retomar as leituras de Pimpa, e seguir adiante com as aulas de Filosofia, porém as crianças não paravam de falar na eleição, na dor, na perda, e um sentimento de solidariedade ao candidato vencido conquistou

\footnotetext{
" Professora PPG PL I do Programa de Pós-Graduação em Educação da Universidade Tiradentes (UNIT).rosanafernandes.edu@gmail.com

** Universidade Tiradentes - UNIT, Aracaju, Brasil. fabricia.borges@gmail.com
}

FERNANDES, Rosana Aparecida; BORGES, Fabrícia Teixeira. O que podem as crianças? Revista Sul-Americana de Filosofia e Educação. Número 18: maio-out/2012, p. 260-270. 
quase todos os alunos ali presentes. A professora não sabia mais o que fazer para encerrar aquela espécie de manifestação e voltar à Pimpa. Como estratégia para iniciar a aula, e finalizar a conversa, a professora ligou o gravador que era utilizado nas aulas de Filosofia. Mas não funcionou. Rafael, um dos alunos, pegou o livro da Pimpa, e perguntou à professora: "Nós não podemos ao invés de ler Pimpa escrever uma carta para o Cristovam, profe?". Hesitante e confusa a professora respondeu: "Nós estamos atrasados na nossa leitura, as outras turmas estão bem mais adiantadas". E Rafael insistiu: "Mas profe Rosana, hoje a aula não é de Filosofia?". "Sim, Rafael, a aula é de Filosofia". Felipe uniu-se ao questionamento de Rafael e continuou: "Então, profe, nós temos o direito de manifestar nossa amizade pelo governador Cristovam. A gente falou tanto sobre direito e justiça outro dia quando líamos a Pimpa, e agora não podemos praticar os nossos direitos?". E Ana completou: "Todo mundo aqui sabe que foi injustiça o Cristovam perder, teve muita gente que vendeu o voto por um botijão de gás lá na Samambaia". Alice incluiu no debate: "Como é que o Roriz vai pagar os $28 \%$ de aumento para os professores, profe, é mentira dele, ninguém sabe quais as intenções verdadeiras dele". Ana concluiu: "A gente sabe muito bem quais são as intenções de alguém que dá botijão de gás para os pobres antes da eleição". E José deu seguimento à discussão que não parecia ter fim: "O Roriz vai ter que pedir dinheiro para o outro país e vai ter que aumentar o imposto de renda pra poder pagar esses 28\%". Alice comentou: "Quando o Roriz sair do governo eu vou ter 13 anos, nós vamos ter que aguentar até lá, não temos saída, os direitos são iguais para todos, mas eu nunca vou deixar de ser petista".

Em meio a tudo isso, ainda vacilante, mas quase convencida, a professora abriu o armário, pegou folhas pautadas, e entregou às crianças, pedindo que elas escrevessem a carta que desejavam escrever para o governador Cristovam. Quando tudo parecia resolvido, Maíra trouxe mais um elemento para aquela manhã um tanto complicada para a jovem professora: "Profe, você não pode ir à casa do Cristovam entregar as nossas cartas para ele?". Sem ânimo, mas também sem resistência, a professora respondeu: "Sim. Ele mora na Asa Norte, um amigo sabe o endereço, vou pedir, e deixarei com o porteiro do prédio. Está bom 
assim?". As crianças já não estavam tristes e abatidas como no início da aula, a possibilidade da comunicação com o Cristovam Buarque devolveu-lhes a agitação $e$ a animação que lhes era comum, aumentou-lhes a potência de pensar e de agir. Talvez a aflição da professora estivesse ligada à incapacidade dela em entender que as crianças estavam afetadas pela eleição, e que isso não era um impeditivo para a aula de Filosofia acontecer, inclusive porque o pensamento se faz exercer justamente aí: quando os corpos são tocados, impelidos, afetados por um signo. $\mathrm{O}$ que faltava àquela professora? O que Lipman diria a ela? Na ocasião a professora se espantou com a apropriação que as crianças fizeram de Pimpa, com o quanto o trabalho realizado nas aulas de Filosofia extrapolou as leituras e as discussões feitas em sala, e adquiriu outras expressões por meio das posturas das crianças diante das circunstâncias cotidianas. O fato ocorrido fez a professora refletir sobre a ligação entre a Filosofia para Crianças e o que se passa na vida, e nisso as crianças foram mais rápidas que a professora.

O pensamento manifestado, verbalizado e construído por aquelas crianças indicava certa disposição em construir ideias alheias à normatização aplicada pelo senso comum, e pelo pensamento dogmático dominante e frequente. É fácil ir à casa de uma pessoa, seja ela quem for. As crianças não enxergavam impossibilidades em entregar as cartas para o Cristovam. O processo de imaginação e de criação da criança pode ser amplo, Lipman e Sharp, se dedicaram a investigar e estender esta potencialidade. Naquela ocasião as crianças desafiavam o pensamento corrente a pensar o impensado, imaginar, fabular, deslizar entre normativas, fatos, regras, direitos, deveres. $\mathrm{E}$ as relações se apresentavam desprovidas de outras leis que não a da amizade, como a de Pimpa e Bel. Por isto aquelas crianças podiam pensar criativamente: a amizade se fez condição para pensar, e levou as crianças para um espaço-tempo no qual a amizade é um traço vivo do pensamento. "Nós nem sequer sabemos de que é capaz um corpo" (SPINOZA, 2007, p. 167). E a circunstância configurou-se de modo a ensinar para a professora que o aprendizado das posturas, pensamentos, atitudes e afecções que cada corpo é capaz de efetuar, se dá mediante o percurso e o percorrido, os encontros, e os acontecimentos. Assim, a professora, guiada pelas crianças, pode 
extravazar os contextos da novela de Lipman, afinal, as novelas provêm da vida, e desejam aumentar a potência de pensar, viver, e de agir das crianças, jovens, e professores.

Enquanto andávamos pelo corredor, a Bel e eu íamos de mãos dadas como nós sempre fazíamos. Não falávamos nada, porque cada uma de nós estava pensando. Eu estava pensando em como eu era sortuda por ter uma amiga que não tentaria descobrir um segredo meu. (LIPMAN, 1997, p. 6).

A amizade de Pimpa e Bel circula por toda a novela e, de certa forma, nutre a amizade das crianças com o candidato Cristovam:

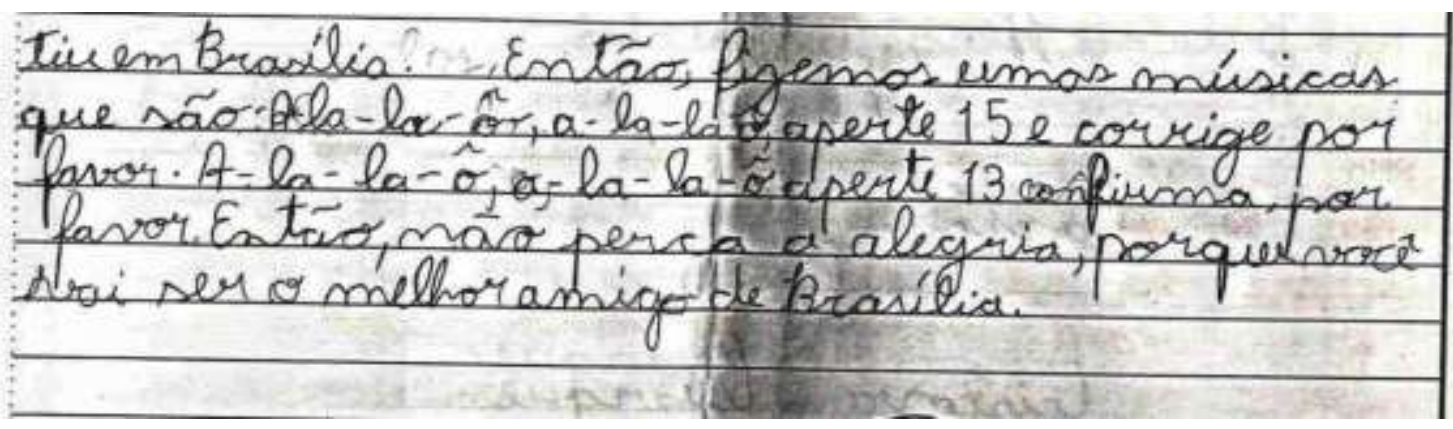

Não obstante, ao término da aula a professora Rosana se viu com as cartas na mão, e se sentiu ainda mais angustiada com os atrasos na leitura de Pimpa. Pensou, e fez a única coisa que poderia fazer: tirou cópia das cartas antes de entregar os originais ao ex-governador Cristovam Buarque. As cópias das cartas foram guardadas. Treze anos depois continuavam arquivadas. Contudo, em decorrência da escrita de um ensaio, para um livro em homenagem ao Matthew Lipman e à Ann Sharp, a professora abriu a caixa na qual mantém as cópias, moveu uma a uma, e se perguntou: como aquele dia de 1998, as cartas e o posicionamento daquelas crianças se interligam com a teoria e a metodologia criadas por Matthew Lipman e Ann Margaret Sharp? Interessada pelas forças que atravessam uma Comunidade de Investigação Filosófica, alterando os modos como as crianças se inserem nas cenas cotidianas, a professora, junto com uma amiga, também conhecedora das propostas de Lipman e Sharp, se propõe a mapear, neste paper, as afecções que fizeram aquela $2^{\mathrm{a}}$ série se apropriar de Pimpa e experimentar na fala e no pensamento os conceitos estudados, articulando-os com situações da vida. Ao cruzar as cartas, a gravação da discussão, e o livro Pimpa a 
professora faz a pergunta o que podem as crianças?, de que afectos são capazes?. Para se pensar há de se encontrar com signos que coagem o pensamento, arrancam-no da opinião, e jogam-no numa operação inventiva e problematizante, e as crianças de 1998 começaram a ensinar essa operação para a professora.

A Filosofia para Crianças jamais se limita às leituras das novelas, ela vai além, e faz variar o pensamento, expande-o e vincula-o à vida, através de um processo dialógico (cf. LIPMAN, 1995; BAKHTIN, 2005), no qual a linguagem orienta o pensamento e o conduz à criação e à possibilidade de reinvenção das experiências vividas. O pensamento se faz possível por meio de uma mediação semiótica, enunciada pela linguagem em uma vivência contextualizada, e possível em um tempo e um espaço organizados. Nesse sentido, o tempo e o espaço organizados na sala de aula que experimenta a Filosofia são articulados $e$ expressos através da constituição da Comunidade de Investigação Filosófica. E é em uma Comunidade de Investigação Filosófica que as crianças, daquela turma de 1998, se propuseram a pensar, com a professora, as inquietudes sucedidas a partir da vivência de uma situação política. Ora, estar vivendo a política em um centro organizado pela política não é algo que escapa ao cotidiano. As crianças mencionadas vivem em um sociedade que as fazem pensar politicamente, muitas vezes mediadas por seus pais, amigos e professores, o que configura uma oportunidade verdadeira de expressão do espírito democrático, voltado para a construção e a vivência da cidadania.

Seguidamente, nas aulas de Filosofia as intervenções são retóricas, mentirosas. As perguntas ficam na superfície. E a professora já tinha se deparado com essa constatação em outros momentos. Porém, a conjuntura vivenciada naquele dia, por ocasião de um acontecimento político, era justamente o inverso disso. As crianças faziam as perguntas que importavam, que lhes aumentavam a potência de pensar. E não há meios para se saber o que pode uma criança, até onde ela pode ir, antes que ela viva as experiências que desejar e encontrar em seus caminhos. Os modos de subjetivação estão inevitavelmente entrelaçados com as relações estabelecidas com o mundo. Concretamente, responder à pergunta "o que podem as crianças?" exige que nos dirijamos para os afectos de que elas são 
capazes, o poder de serem afectadas, os estímulos a que reagem ou permanecem indiferentes. E como não ser afectado pelo contexto caloroso e entusiástico que circulava no momento político daquela cidade? Como não sentir que uma passeata de vitória do outro candidato, que não o seu, poderia virar uma "passeata da tristeza"?

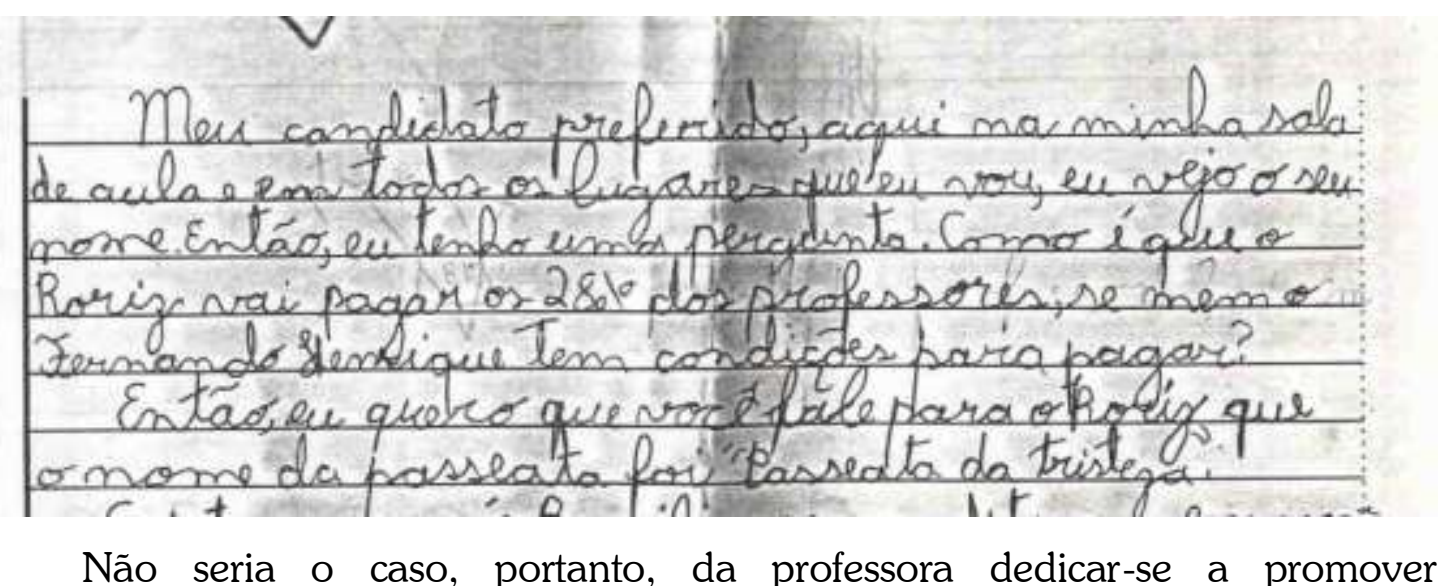
intervenções sinceras, comprometidas com a investigação do problema, com a constituição dele, sem querer direcionar o pensamento das crianças para um fim prévio, uma conclusão anterior à discussão filosófica? As novelas e os manuais propostos por Lipman não desejam jamais engessar uma aula, uma discussão filosófica. A aula é um acontecimento extemporâneo, e o seu duplo é o inesperado. As leituras das novelas, quando cruzadas com o cotidiano, fazem as páginas lidas vivas, e por isso podem alterar o trajeto do que havia sido previsto durante o planejamento. Estar sensível aos signos que atravessam a sala de aula é, pois, um constante exercício a ser desempenhado pelo docente, a fim de que o planejamento volte-se para o ritmo, os movimentos e os rumos da discussão filosófica, não o contrário.

Com efeito, a vida e a Filosofia sempre estiveram intimamente relacionadas. Tendem a se coincidir e a compor uma "unidade complexa: um passo para a vida, um passo para o pensamento. Os modos de vida inspiram maneiras de pensar, os modos de pensar criam maneiras de viver" (DELEUZE, 1994, p. 17-18). Os problemas filosóficos e os conceitos são inventados com base em necessidades colocadas pela vida mesma, eles respondem a verdadeiros e vitais problemas. A filosofia firma uma aliança ativa com a vida, com o mundo e com domínios não 
filosóficos. No entanto, os questionamentos de uma criança, advindos desses encontros com o mundo, nem sempre recebem a consideração e o desenlace que merecem. De fato, são inúmeras as situações nas quais as crianças são privadas da efetuação da potência de seus pensamentos e, por conseguinte, de aprender suas capacidades, suas possíveis atitudes ou posturas. Todavia, é isso que é pensar: colocar-se nesse aprendizado e pôr-se a pensar justamente o que escapa ao óbvio, ao que é novo e inopinado.

Vale salientar, ainda, que a conversa que as crianças tiveram, no começo daquela aula, demonstram que elas estavam partilhando um problema com um fundo comum, que remontava à constituição de conceitos, como: direito, justiça, democracia. Elas se puseram a pensar sob a urgência de um problema acionado por elas, o qual edificava-se pleno de sentido, desde que suscitava nelas questões, embrenhava-se num mundo vivido por elas e se fazia absolutamente concreto. A carta abaixo é de Márcia ${ }^{1}$ ( 9 anos):

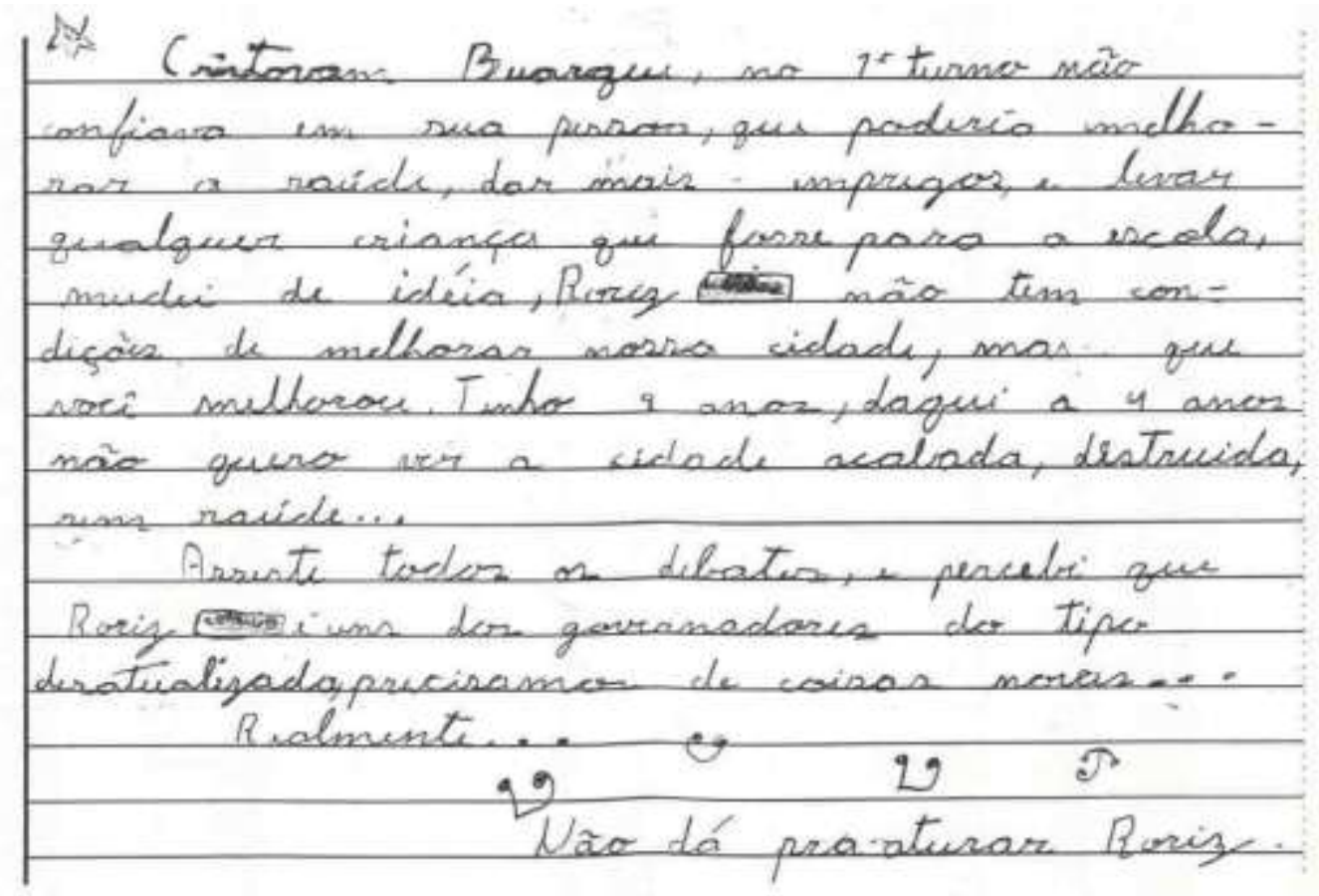

Existe uma história na carta de Márcia que evidencia a construção lógica de seu pensamento acerca da preferência pelo candidato Cristovam Buarque. E a sua lógica não remonta a um aspecto individual, mas a uma preocupação coletiva com a cidade, a saúde, a escola para as crianças. Nove anos. Nove anos é a idade de

\footnotetext{
${ }^{1}$ Nomes fictícios.
} 
Márcia que consegue se transportar para os quatro anos vindouros. E ela consegue realizar esta operação mediante a capacidade de se imaginar em um futuro (VIGOTSKI, 2009), de se pensar em uma cidade que não gostaria de viver. Ela emite valores, pensa sobre eles, faz uma escolha de candidato, mas uma escolha evidenciada por uma lógica de pensamento, por uma concepção histórica, acrescida de uma experiência coletiva. Trata-se de uma potência do pensar, contagiado pela lógica do social, do cotidiano, do democrático. Em consonância, as novelas de Lipman apresentam estórias que contam histórias da vida, estórias que se propõem a pensar questões que circulam coletivamente, num movimento dialógico entre texto e vida, entre autores e personagens, heróis e pessoas (BAKHTIN, 2000). Nas cartas das crianças, Pimpa e Bel mudaram de nome e passaram a ser: Felipe, Ana, Roriz, Cristovam, Fernando Henrique, Márcia, Maisa, Rafael, Rosana. As Pimpas corriam soltas e atravessavam os campos de Brasília, chegavam ao Congresso Nacional, questionavam o local da cidadania, do ter escola, do ter saúde, do ser coletivo. A carta de Renato diz:

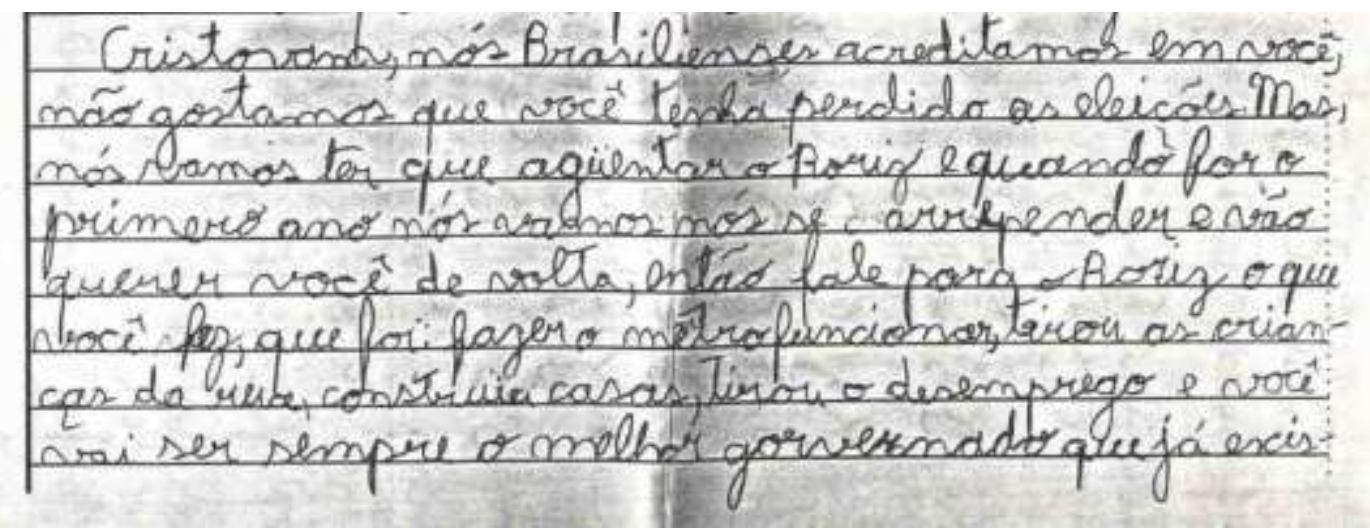

A carta acima demonstra a inserção desta criança nos grupos sociais. Os afectos são vivenciados coletivamente, no gostar e no acreditar. A projeção no tempo futuro indica a capacidade imaginativa na qual Renato vivencia sua possibilidade de antecipar o tempo, as emoções e fazer previsões, como Pimpa. A temporalidade da carta mescla o pensar anacrônico, mas contextualizados nas sensações do presente. A previsão de novos sentimentos reside em um olhar restrospectivo de ações históricas sobre o que o canditado Cristovam executou em seu governo. O pensamento revela-se histórico, evidencia a capacidade de 
articulação entre as várias temporalidades, num movimento semiótico (VALSINER, 1989).

$\mathrm{Na}$ relação entre palavras e pensamentos as crianças vivenciaram os sentimentos daquele momento histórico, como fato de vida e de expressão. Puderam questionar, se emocionar, enfatizar e exclamar. Mas, puderam, antes de mais nada, pensar. Tiveram permissão para pensar, pois a sala de aula de Filosofia se constituiu como local e momento do pensar: "Mas profe Rosana, hoje a aula não é de Filosofia?". O exercício do pensar naquela experiência aconteceu porque existia um momento constituído para que a vida pudesse ser problematizada, através do encontro entre professora, alunos, crianças, cidadãos, candidatos políticos, cidade de Brasília, país Brasil.

Em suma, a professora pode ouvir, modificar-se e apreender algo mais sobre as possibilidades da proposta de Lipman e Sharp. A Pimpa não cedeu lugar para a professora e as crianças questionarem os acontecimentos políticos da época, a Pimpa estava junto o tempo todo, atravessava o pensamento das crianças, da professora, os espaços da sala de aula. Junto a isto circulava as emoções, os afectos, a possibilidade do diálogo, perspectivas da democracia conectada à vida. E a carta alcançou a dimensão de um diálogo íntimo e de uma atitude democrática. Na escrita e nos desenhos, pensamentos e afecções tomaram forma, $e$ foram expressos através de palavras, traços, cores. E as crianças brincaram com elementos vindos de distintos lugares: mídia, panfletos, textos, vozes, anúncios, debates políticos, etc.

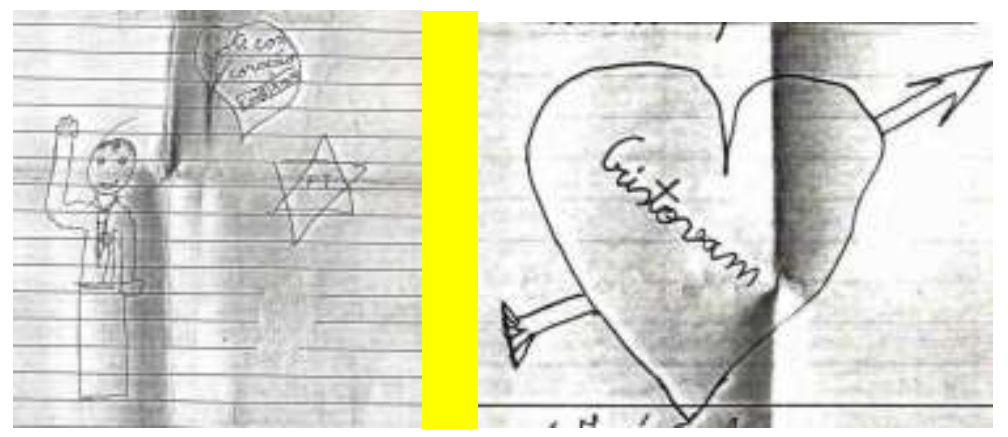

Nos desenhos encontram-se o lúdico, a imaginação, a linguagem icônica, a figuração dos fatos e dos pensamentos. Nas cartas, alguns desenhos 
eram apropriações vindas das mídias que circulavam naquele momento, mas ganhavam expressão, alegria e vida nas mãos dos autores das cartas: as crianças. Essa recriação das crianças a partir dos emblemas midiáticos, dos candidatos e dos partidos permite a criança imaginar um mundo a partir de suas próprias percepções e criações. Para Benjamin (1994), a criança cria heterogêneos, embaralha elementos advindos de seus contatos e vivências com a realidade, implica, une.

Se além disso pensamos na criança que brinca, podemos falar de uma relação antinômica. Por um lado, verifica-se que nada é mais próprio da criança que combinar imparcialmente em suas construções as substâncias mais heterogêneas - pedras, plastilinas, madeira, papel. (BENJAMIN, 1994, p. 246)

As imagens presentes nas cartas sugerem esta brincadeira. Se Benjamin (1994) destaca o fascínio das crianças pelas oficinas de construir e reconstruir a partir de materiais diversos; colocamos, aqui, que na aula de Filosofia as cartas foram também o lugar da "oficina" das crianças, onde ideias, pensamentos, e sensações se fizeram presentes, tanto no texto quanto no entorno e expressões diversas. Decerto, naquela circunstância, a sala de aula constituiu-se como o lugar da oficina do pensar e do exprimir-se, de uma amizade encarnada, de uma democracia vivida, questionada, avaliada.

\section{Referências bibliográficas}

BAKHTIN, Mikhail. A cultura popular na Idade Média e no Renascimento: o contexto de François Rabelais. 2. ed. São Paulo, Edunb: Ubitec, 1993.

A estética da criação verbal. São Paulo: Martins Fontes, 2000.

- Problemas da poética de Dostoiésuski. Rio de Janeiro: ForenseUniversitária, 2005.

BENJAMIN, Walter. Magia e técnica, arte e política: ensaios sobre a literatura e história da cultura. 7a . Ed. São Paulo: Brasiliense, 1994.

DELEUZE, Gilles. Nietzsche. Lisboa: Edições 70, 1994.

KENNEDY, David; KOHAN, Walter Omar (Orgs.). Filosofia e Infância: possibilidades de um encontro. Petrópolis, RJ: Vozes, 1999. v. 3. (Filosofia e Crianças.) 
LIPMAN, Matthew. A filosofia vai à escola. Tradução de Maria Elice de Brzezinski Prestes e Lucia Maria Silva Kremer. São Paulo: Summus, 1990.

- O pensar na educação. Tradução de Ann Mary Fighiera Perpétuo. Petrópolis, RJ: Vozes, 1995.

. Pimpa. Tradução de Sylvia Judith Hamburger Mandel. São Paulo: Difusão de Educação e Cultura, 1997.

SPINOZA, Benedictus de. Ética. Tradução de Tomaz Tadeu. Belo Horizonte: Autêntica Editora, 2007.

VALSINER, Jaan. Human development and culture: The social nature of personality and its study. Lexington, MA: Lexington, 1989.

VIGOTSKI, Lev. A formação social da mente. São Paulo, Martins Fontes, 1989. 2001. A construção do pensamento e da linguagem. São Paulo: Martins Fontes, 2009. Imaginação e criação na infância: ensaio psicológico. São Paulo: Ática, 